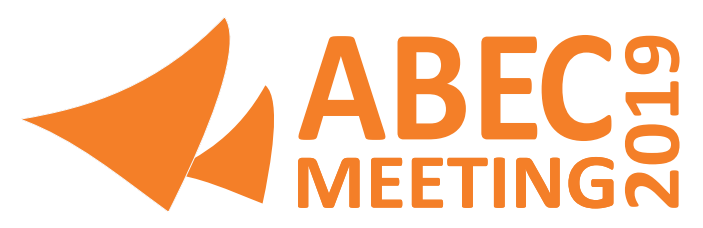

SEPT 17-20

UNIFOR

FORTALEZA

CE - BRAZIL
EDITOR'S

CHALLENGES

FOR OPEN SCIENCE

\title{
REVISTA BRASILEIRA DE EDUCAÇÃO DO CAMPO: TRAJETÓRIA, DESAFIOS E PERSPECTIVAS
}

\author{
Revista Brasileira de Educação do Campo (Brazilian Journal of Rural Education): \\ Trajectory, challenges and perspectives
}

\author{
Gustavo Cunha de Araújo \\ Universidade Federal do Tocantins
}

\section{COMO CITAR}

ARAÚJO, Gustavo Cunha de. Revista Brasileira de Educação do campo: trajetória, desafios e perspectivas. In: ABEC MEETING, 2019, Fortaleza. Anais... São Paulo: Associação Brasileira de Editores Científicos, 2019. http://dx.doi.org/10.21452/abecmeeting.2019.197

\section{RESUMO}

Por meio de uma perspectiva histórica, apresentamos alguns pontos da trajetória da Revista Brasileira de Educação do Campo (RBEC), os desafios enfrentados enquanto periódico científico durante os seus 3 (três) anos de existência e suas perspectivas futuras para a comunidade científica. Para concretizar o projeto da revista, realizamos um trabalho exaustivo de estudo e pesquisa em revistas renomadas da área educacional brasileira e de periódicos estrangeiros com fator de impacto, para conhecer e tentar compreender como é estruturada uma revista científica. Foi a partir dessa trajetória, que surgiu a Revista Brasileira de Educação do Campo. Dentre alguns resultados, a partir desses primeiros 3 (três) anos da RBEC, compreendemos que ser editor de um periódico não significa apenas coordenar uma revista, mas buscar atender as expectativas da comunidade acadêmica e se atualizar constantemente com as informações a respeito da ciência internacional e editoração. É manter uma relação profissional, ética e de respeito com leitores, avaliadores e autores, ao ampliar a produção de conhecimento e torná-lo acessível a todos. Com efeito, entendemos que estudar e pesquisar revistas internacionais de alto impacto e se atualizar com novas informações a respeito da editoração científica nacional e internacional pode ser um primeiro passo para tentar construir um periódico de qualidade e acessível a todos.

\section{PALAVRAS-CHAVE}

RBEC. Educação do Campo. Editoração. Publicação Científica 


\section{ABSTRACT}

From a historical perspective, we present some points of the trajectory of the Revista Brasileira de Educação do Campo (RBEC) (The Brazilian Journal of Rural Education), the challenges faced as a scientific journal during its 3 (three) years of existence and its future perspectives for the scientific community. In order to accomplish the journal's project, we carried out an exhaustive study and research in renowned Brazilian educational journals and foreign journals with impact factor, to know and try to understand how a scientific journal is structured. It was from this trajectory that the Revista Brasileira de Educação do Campo emerged. Among some results, from these first 3 (three) years of RBEC, we understand that being an editor of a journal does not only mean coordinating a journal, but seeking to meet the expectations of the academic community and constantly update itself with information regarding international science and publishing. It is to maintain a professional, ethical and respectful relationship with readers, reviewers and authors, by expanding the production of knowledge and making it accessible to all. Indeed, we understand that studying and researching high-impact international journals and updating with new information about national and international scientific publishing can be a first step in trying to build a quality journal accessible to all.

\section{KEYWORDS}

RBEC. Rural Education. Publishing. Publishing Scientific.

\section{INTRODUÇÃO}

Por meio de uma perspectiva histórica, apresentamos alguns pontos que revelam a trajetória da Revista Brasileira de Educação do Campo (RBEC), bem como os desafios enfrentados enquanto periódico científico durante os seus 3 (três) anos de existência e perspectivas futuras de sua equipe editorial para a comunidade científica.

A Revista Brasileira de Educação do Campo é um periódico de publicação contínua, de acesso aberto, blind review, que publica artigos originais e revisões teóricas, ensaios, dossiês, entrevistas e resenhas a respeito da Educação do Campo no Brasil e em outros países, em diálogo com as suas variáveis, a saber: movimentos sociais, formação de professores, pedagogia da alternância, povos indígenas, questões agrárias, políticas públicas, educação de jovens e adultos, artes, didática e práticas pedagógicas e interculturalidade. Publica nos idiomas português, inglês e espanhol, e conta com uma diversidade institucional de pesquisadores brasileiros e estrangeiros em sua equipe editorial. Atualmente, além de adotar a Publicação Contínua (PC), a revista já publicou 9 (nove) números de suas edições, contendo artigos de pesquisadores nacionais e internacionais de diferentes instituições, que podem ser acessados no próprio site da revista, hospedado no Portal de Periódicos da Universidade Federal do Tocantins.

É importante ressaltar que a Revista Brasileira de Educação do Campo é um periódico relevante na área da Educação no Brasil, o que a coloca como um importante veículo de comunicação científica de potencial para novos debates e pesquisas produzidas nessa área no país e em outras nações. A revista recebe manuscritos em fluxo contínuo, além de abrir chamadas de trabalhos ao longo do ano (Call for Papers). É um periódico científico de acesso aberto, on-line 
(formato eletrônico) e gratuito, sem taxas de submissão e de publicação dos textos submetidos. Os artigos recebidos são avaliados em blind review por pareceristas e avaliadores ad hoc da área de conhecimento da revista, conforme Conselho Editorial. Caso sejam aceitos, os manuscritos são publicados nesse periódico no formato de publicação contínua.

Para complementar essa política editorial, a RBEC tem como missão ser um veículo de comunicação científica de qualidade internacional que fomente importantes debates no campo educacional, principalmente na área da Educação do Campo, de pesquisadores brasileiros e estrangeiros, para o avanço científico da área na ciência nacional e internacional e para a produção de conhecimento.

\section{RESULTADOS E DISCUSSÃO}

A Revista Brasileira de Educação do Campo (RBEC) surgiu há 3 (três) anos, por meio de conversas com colegas do colegiado do curso de Educação do Campo com habilitação em Artes e Música da Universidade Federal do Tocantins, campus de Tocantinópolis e pelo interesse, de seu atual Editor-Chefe, de coordenar um periódico científico. Motivados por esse interesse, somado a carência de pesquisas acerca da Educação do Campo no Brasil (em comparação com outras temáticas educacionais), averiguamos que não havia no país uma revista específica que abordasse a temática "Educação do Campo" em consonância com as temáticas do curso (artes e formação de professores, entre outros).

Nesse sentido, para concretizar o projeto da revista, foi feito um trabalho exaustivo de estudo e pesquisa em revistas renomadas da área educacional brasileira e de periódicos estrangeiros com fator de impacto, para conhecer e tentar compreender como é estruturada uma revista científica. Foi a partir desse caminho traçado, que surgiu a Revista Brasileira de Educação do Campo.

No que se refere à inserção da revista em bases de dados nacionais e internacionais, desde a sua criação em 2016, conseguimos indexá-la em bases relevantes que a ajudaram a conseguir o DOI com menos de 1 (um) ano de existência. Nesse caminho, em busca de qualidade constante na revista, entramos em contato com a Web of Science (Emerging Sources Citation Index) e, após a avaliação feita por essa base que durou aproximadamente 1 (um) ano e meio, a RBEC foi aceita para compor a sua coleção, isso, com apenas 2 (dois) anos de existência, o que representa uma conquista significativa para a comunidade acadêmica e reconhecimento do trabalho feito nesse periódico.

Nesse processo, ressaltamos também a publicação de artigos estrangeiros de diferentes países na revista, que revela uma aceitação do periódico pela comunidade internacional, ao encontrar nessa revista trabalhos de qualidade a partir de diferentes abordagens e temas, além de um trabalho sério e ético desenvolvido pela sua equipe editorial.

No ciclo em discussão, importa chamar atenção, entretanto, que nos últimos 3 (três) anos, a RBEC conseguiu concretizar como parte de sua política editorial:

a) Publicação Contínua como periodicidade da revista.

b) Endogenia extremamente baixa (menos de 10\% por número ou volume, tendo 
sido zero em 2017).

c) Atendimento as boas práticas de publicação na ciência nacional e internacional.

d) Indexada em 59 bases (diretórios, repositórios etc.), entre nacionais e internacionais.

e) Na esteira desse pensamento, conseguiu ainda publicar:

f) Artigos internacionais publicados: 20

g) Artigos nacionais publicados: 151

h) Artigos publicados até hoje (agosto de 2019): 171

É essencial assinalar que nesse percurso, os principais desafios à frente da revista são:
a) Prazos de avaliação (pareceristas em atraso ou que não respondem o convite);
b) Envio de artigos nas normas da revista;
c) Ética na pesquisa.
d) Indexação na Scielo;
e) Indexação na Scopus;
f) Aumentar o número de artigos internacionais;
g) Aumentar o número de artigos de doutores;
h) Aumentar o número de artigos de instituições diferentes;
i) Aumentar o número de avaliadores;
j) Aumentar o número de artigos vinculados a programas de pós-graduação;
k) Aumentar o rigor nas avaliações dos artigos recebidos;
l) Aumentar a quantidade de artigos em outros idiomas (preferencialmente o inglês).
m) Inserção em bases elevadas da Web of Science para ter Fator de Impacto (FI) da JCR;

n) Consolidação da revista na comunidade acadêmica nacional e internacional da área.

No que se refere às expectativas, são positivas com relação à editoração científica nos próximos anos, porém, desafiadoras, uma vez que a editoração científica está em constante atualização no cenário internacional, o que implica em uma atenção maior por parte de editores de periódicos nacionais e estrangeiros para que possam acompanhar esse processo, como, por exemplo, o debate acerca do acesso aberto e os pré-prints, que podem acelerar ainda mais o processo de publicação na comunicação científica, ao contribuir para a produção de conhecimento. Com efeito, é importante editores estarem atentos a esse processo, uma vez que pode afetar diretamente na melhoria e no desenvolvimento das revistas que coordenam. 


\section{CONSIDERAÇÕES FINAIS}

A partir desses primeiros 3 (três) anos de Revista Brasileira de Educação do Campo, compreendemos que ser editor de um periódico não significa apenas coordenar uma revista, mas buscar atender as expectativas da comunidade acadêmica e se atualizar constantemente com as informações a respeito da ciência internacional e editoração. É manter uma relação profissional, ética e de respeito com leitores, avaliadores e autores, ao ampliar a produção de conhecimento. Com efeito, entendemos que estudar e pesquisar revistas internacionais de alto impacto e se atualizar com novas informações a respeito do que vem sendo discutido na editoração científica nacional e internacional, pode ser um primeiro passo para tentar construir um periódico de qualidade e acessivel a todos.

\section{REFERÊNCIAS}

Revista Brasileira de Educação do Campo. Disponível em: https://sistemas.uft.edu.br/periodicos/index.php/campo. Acesso em: 19 set. 2019. 